\title{
Ti-doped isotropic graphite: a promising armour material for plasma- facing components
}

\author{
C. García-Rosales ${ }^{1 *}$, I. López-Galilea ${ }^{1}$, N. Ordás ${ }^{1}$, C. Adelhelm², M. Balden ${ }^{2}$, \\ G. Pintsuk ${ }^{3}$, M. Grattarola ${ }^{4}$, C. Gualco ${ }^{4}$ \\ ${ }^{1}$ CEIT and Tecnun (University of Navarra), E-20018 San Sebastián, Spain \\ ${ }^{2}$ Max-Planck-Institut für Plasmaphysik, EURATOM Association, D-85748 Garching, Germany \\ ${ }^{3}$ Forschungszentrum Jülich GmbH, EURATOM Association, D-52425 Jülich, Germany \\ ${ }^{4}$ Ansaldo Ricerche S.p.A., I-16152 Genoa, Italy
}

\begin{abstract}
Finely dispersed Ti-doped isotropic graphites with 4 at $\%$ Ti have been manufactured using synthetic mesophase pitch "AR" as raw material. These new materials show a thermal conductivity at room temperature of $\sim 200 \mathrm{~W} / \mathrm{mK}$ and flexural strength close to $100 \mathrm{MPa}$. Measurement of the total erosion yield by deuterium bombardment at ion energies and sample temperatures for which pure carbon shows maximum values, resulted in a reduction of at least a factor of 4 , mainly due to dopant enrichment at the surface caused by preferential erosion of carbon. In addition, ITER relevant thermal shock loads were applied with an energetic electron beam at the JUDITH facility. The results demonstrated a significant improved performance of Ti-doped graphite compared to pure graphite. Finally, Ti-doped graphite was successfully brazed to a CuCrZr block using a Mo interlayer. These results let assume that Ti-doped graphite can be a promising armour material for divertor plasma-facing components.
\end{abstract}

\footnotetext{
* Corresponding author CEIT and Tecnun (University of Navarra) Paseo de Manuel Lardizabal, 15 E-20018 San Sebastian, Spain. Tel.: +349432128 00; fax +34943213076

E-mail address: cgrosales@,ceit.es
} 


\section{Introduction}

Carbon fibre-reinforced carbon (CFC) is envisaged for the strike point area of the ITER divertor due to its excellent resistance to excessive heat loads during off-normal events such as plasma disruptions and edge-localized modes (ELMs) [1]. Besides the high cost, long delivery time and large variations in properties of the CFCs developed for ITER [2], a main drawback of carbon-based materials is their chemical erosion under hydrogen bombardment from the plasma during normal operation [3], leading to a high tritium amount accumulated in re-deposited carbon layers. In addition, recent results show that the retention of implanted hydrogen isotopes in CFC increases continuously with ion fluence, while in finegrain graphite quasi-saturation of the retention occurs, so that at the fluences reached in today's fusion devices within a typical experimental campaign the retention in $\mathrm{CFC}$ can exceed the retention in finegrain graphite by one order of magnitude [4]. Furthermore, under intense transient heat loads CFCs show a preferential erosion of the fibres aligned in the loaded-surface plane [5], while in fine-grain graphite the erosion by brittle destruction leads to a rather homogeneous erosion pattern [6].

Previous work $[7,8]$ reveals that doped isotropic graphite shows significantly improved performance as plasma-facing material compared to pure graphite: the addition of $\mathrm{Ti}$ as dopant not only reduces the chemical erosion of carbon [9], but it leads also to a substantial increase of thermal conductivity and mechanical strength [7]. Besides, the deuterium retention behaviour of doped graphite is comparable to that of pyrolytic graphite [10], with quasi-saturation at low fluences. These facts let assume that Ti-doped isotropic graphite may be an attractive, low cost plasma-facing material able to compete with present CFC candidate materials.

In this paper the results of several tests of high relevance for plasma-facing application are shown on newly developed Ti-doped graphites: erosion by deuterium bombardment, thermal shock loads under ITER disruption conditions and joining to a $\mathrm{Cu}$-based heat sink by brazing.

\section{Experimental}

As starting carbon raw material a self-sintering synthetic mesophase pitch named “AR" from Mitsubishi Gas Chemical was used. An oxidative stabilization step is required previous to mixing and forming to avoid swelling during carbonization due to a strong release of volatiles. The average particle size of the stabilized powder is $<10 \mu \mathrm{m}$. Ti was introduced in form of TiC nanopowder (Sigma Aldrich) with an average particle size of $130 \mathrm{~nm}$. The carbide was added to the carbon raw powder so as to obtain a final 
graphitic material with $\sim 4$ at.\% Ti. Several samples were also produced containing, in addition to TiC, also a small amount of $\mathrm{SiC}(\sim 0.5$ at.\% $\mathrm{Si})$, with the aim to further increase the thermal conductivity, taking advantage of the high graphitization degree of the carbon precipitated by the decomposition of SiC $\left(2540^{\circ} \mathrm{C}[11]\right)$, as reported in [12]. The average particle size of the initial SiC powder was $20 \mathrm{~nm}$. The manufacturing procedure and the material characterization are described in detail in [13]. In Table 1 some typical properties of the manufactured materials (undoped, Ti-doped and Ti-Si-doped) after graphitization at $2765^{\circ} \mathrm{C}$ are shown. It can be observed that the addition of a small amount of $\mathrm{SiC}$ results in thermal conductivities at room temperature (RT) close to $200 \mathrm{~W} / \mathrm{mK}$, but care has to be taken during graphitization to avoid swelling and cracking due to a fast Si evaporation [13]. On the other hand, for samples doped with only $\mathrm{TiC}$ a proper choice of the graphitization parameters [13] leads to even higher thermal conductivity values, avoiding the problems arising from Si evaporation during graphitization.

The erosion of the Ti-doped graphite $A T$ by deuterium ions were studied at the high current ion source at IPP Garching [14]. This source produces a mass-separated monochromatic ion beam. A flux density of $\sim 10^{19} \mathrm{D} / \mathrm{m}^{2} \mathrm{~s}$ was achieved, with an eroded area of $\sim 0.5 \mathrm{~cm}^{2}$. Ion energies of 30 and $200 \mathrm{eV}$ per D were used. The sample temperature was $630 \mathrm{~K}$ for $30 \mathrm{eV}$ and $820 \mathrm{~K}$ for $200 \mathrm{eV} \mathrm{D}$ bombardment. These temperatures were chosen because they correspond to the maximum value of the total erosion yield of pyrolytic graphite at the respective energy [14]. The low energy value is representative for the so called surface regime $\mathrm{Y}_{\text {surf }}$ of chemical erosion, while the higher energy is representative for the thermally activated regime $\mathrm{Y}_{\text {therm }}[15]$. The samples were heated by electron bombardment from the rear, and the temperature was measured with an infrared pyrometer. The total erosion yield was determined from the accumulated fluence onto the specimen and the total amount of carbon and metal eroded, which was obtained from in-situ weight-loss with a sensitivity of $\pm 1 \mu \mathrm{g}$.

High heat flux tests were performed on all materials from table 1 in the electron beam test facility JUDITH at Forschungszentrum Jülich [5]. A fast beam scanning with frequencies of $\mathrm{f}_{\mathrm{x}}=47 \mathrm{kHz}$ and $\mathrm{f}_{\mathrm{y}}=$ $43 \mathrm{kHz}$ was applied to guarantee a homogeneously loaded area. The acceleration voltage was fixed to 120 $\mathrm{keV}$ and the scanned area was $4 \times 4 \mathrm{~mm}^{2}$. The pulse duration was typically $4-5 \mathrm{~ms}$, and the power density, determined by monitoring the absorbed current, was $\sim 2.4 \mathrm{GW} / \mathrm{m}^{2}$. These shots simulate typical ITER disruption conditions. A CCD camera was used to detect the emission of particles during the thermal load tests. After the tests, the weight change and the erosion crater depths were measured with a microbalance and with laser profilometry, respectively. Due to insufficient reflectivity of the undoped 
graphite samples, profilometry was only performed on the doped materials. The microstructure of the loaded surface was observed by optical and scanning electron microscopy.

For the manufacturing of plasma-facing components joining of a carbon-based material to a $\mathrm{CuCrZr}$ heat sink is required. High temperature brazing is one of the reference methods proposed for ITER. Thus, brazing tests were performed at Ansaldo Ricerche to joint the new developed Ti-doped graphites to pure $\mathrm{Cu}$ and to $\mathrm{CuCrZr}$. To improve the poor wetting of $\mathrm{Cu}$ on graphite, a $\mathrm{Cu}$ active brazing alloy (ABA) with composition $93 \mathrm{Cu}, 2 \mathrm{Ti}, 2 \mathrm{Al}, 3 \mathrm{Si}$ was used, whose solidus and liquidus temperature are $958^{\circ} \mathrm{C}$ and $1024^{\circ} \mathrm{C}$, respectively [16]. The brazing alloy foil was $60 \mu \mathrm{m}$ thick. Brazing was performed under high vacuum at $1035^{\circ} \mathrm{C}$ for $18 \mathrm{~min}$.

\section{Results and discussion}

\subsection{Erosion by deuterium bombardment}

Fig. 1 shows the total erosion yield of the Ti-doped graphite $A T$ versus the incident deuterium fluence under different ion energies and sample temperatures. For $30 \mathrm{eV} \mathrm{D}$ impact and $630 \mathrm{~K}$, which is the temperature at which for $30 \mathrm{eV}$ the maximum total erosion yield for pure $\mathrm{C}$ is found [14], a reduction from 0.08 for pure $C$ to 0.02 at the highest accumulated fluence $\left(1.26 \times 10^{25} \mathrm{D} / \mathrm{m}^{2}\right)$ is observed. At this fluence a steady state of the erosion yield seems to be achieved. Analysis of the surface morphology of the sample before and after bombardment at the highest fluence (Fig. 2) reveals that TiC enrichment at the surface occurred due to preferential erosion of $\mathrm{C}$ : after long fluence bombardment the TiC grains form a shielding network which protects the underlying graphite from further erosion, thus reducing the total erosion, whose main component at this low energy is due to chemical erosion of carbon. It should be notice that at low fluences the total erosion yield of Ti-doped graphite $A T$ is the same as for undoped carbon indicating that there is no chemical influence of $\mathrm{TiC}$ on the electronic structure of carbon in the graphite lattice with could affect $\mathrm{Y}_{\text {surf. For }} 200 \mathrm{eV}$ D impact at the same temperature (which in this case does not corresponds to the maximum erosion yield for pure C) again a strong decrease of the erosion yield with increasing fluence is observed up to the not very high accumulated fluence of $0.64 \times 10^{25}$ $\mathrm{D} / \mathrm{m}^{2}$. Steady state does not seem to be achieved and further reduction would be expected at higher fluences due to $\mathrm{TiC}$ enrichment at the surface. At low fluences, however, a slight decrease of the erosion yield compared to that of pure $\mathrm{C}$ is observed. This effect is much more pronounced for $200 \mathrm{eV} \mathrm{D}$ impact at $820 \mathrm{~K}$, which corresponds to the maximum erosion yield for pure $\mathrm{C}$ at this energy: in this case a 
decrease of the erosion yield from 0.18 (pure C) to $\sim 0.9$ is observed at low fluences. These erosion parameters $(200 \mathrm{eV}, 820 \mathrm{~K})$ are representative for the thermally activated regime $\mathrm{Y}_{\text {therm }}$ of chemical erosion [15], and a reduction of the erosion yield already at low fluences, where a shielding effect of the carbides is not yet possible, indicates an influence of $\mathrm{TiC}$ on this process, inducing most probably a reduction of the activation energy for deuterium release compared to pure C [17]. Even though measurements are only available up to fluences of $0.17 \times 10^{25} \mathrm{D} / \mathrm{m}^{2}$, at which no steady state is yet reached, a strong reduction of the erosion yield with increasing fluence down to at least 0.04 is presumed.

\subsection{Electron beam thermal load tests}

The parameters of the electron beam experiments, which simulate typical disruption conditions, are in the regime well above the threshold for the onset of particle emission due to brittle destruction of fine grain graphite [7]. In fact, large and medium dust particles can be detected by digital imaging during the shot for the undoped $\mathrm{C}$ sample $A$ (Fig. 3), which are associated with significant macroscopic erosion. In contrast, a significant reduction of particle emission and only small dust particles are detected under the same shot conditions for Ti-doped graphite both with (ATS) and without Si (AT). The lower weight loss measured after the shot for these samples (Table 1) is in agreement with this observation. Both weight loss and crater depths are slightly higher for the AT than for the ATS sample, even though the particle emission seems to be slightly less for the $A T$ sample. The reason is probably the higher thermal conductivity of the tested ATS sample ( $200 \mathrm{~W} / \mathrm{mK}$ at RT) compared to $113 \mathrm{~W} / \mathrm{mK}$ for the AT sample. If 10 shots are loaded consecutively on the ATS sample the comparison of particle emission during the first and during the $10^{\text {th }}$ shot reveals a slight decrease after 10 shots. The current plot (current absorbed by the test sample vs. time, Fig. 3) during the $1^{\text {st }}$ shot shows a sudden current spike followed by subsequent spikes probably associated with the emission of dust particles, while during the $10^{\text {th }}$ shot only a sudden current decrease is observed which starts later in time. It is assumed that the spikes during the $1^{\text {st }}$ shot can be (at least partly) due to emission of the small $\mathrm{Si}$ amount present in the sample, since no $\mathrm{Si}$ at all was detected by EDX after the $1^{\text {st }}$ shot, while a clear Si signal could be measured before the thermal load tests.

\subsection{Brazing tests}

First tests were performed to braze Ti-doped graphite $A T$ to a $2 \mathrm{~mm}$ thick $\mathrm{Cu}$ sheet. Brazing was performed to $\mathrm{Cu}$ and not to $\mathrm{CuCrZr}$ because the use of a soft $\mathrm{Cu}$ interlayer was initially planned to miti- 
gate stresses arising from the mismatch of thermal expansion of graphite and $\mathrm{Cu}$ alloys during the brazing process. These tests resulted in good wetting of the $\mathrm{Cu}-\mathrm{ABA}$ with a well formed reaction layer, but cracks were detected within the graphite and some areas of detachment were present. In order to reduce stresses the use of an interlayer with low thermal expansion, such as Mo, was proposed to transfers the residual stresses from the $\mathrm{C}$ surface to the stronger $\mathrm{CuCrZr}$ heat sink one. Thus, a second set of tests were performed by which $8 \mathrm{~mm}$ thick AT and ATS samples were brazed to a $10 \mathrm{~mm}$ thick CuCrZr block using a $2 \mathrm{~mm}$ thick Mo interlayer and the previous $\mathrm{Cu}-\mathrm{ABA}$ as filler alloy. The metallographic examination of the resulting compound revealed the absence of cracks within the graphite and of detachments. A sound joint between the Ti-doped graphite and the $\mathrm{Cu}-\mathrm{ABA}$ was found everywhere with a uniform reaction layer (see Fig. 4). The brazed samples were subjected to thermal shock tests consisting on heating in air up to $450^{\circ} \mathrm{C}$ followed by water quench to RT. The cycles were repeated 25 times without noticing any damage.

\section{Conclusions}

Ti-doped graphites with thermal conductivity $\sim 200 \mathrm{~W} / \mathrm{mK}$ at RT and high mechanical strength have been developed. Several tests of high relevance for plasma-facing application have been performed on these materials leading to the following results:

- The total erosion yield of Ti-doped graphite by deuterium bombardment is reduced by at least a factor of 4 under worst energy and temperature conditions.

- The particle emission and macroscopic damage during disruption-like electron beam loads are significantly reduced compare to undoped $\mathrm{C}$.

- Ti-doped graphite has been successfully brazed to a CuCrZr block using a Mo interlayer.

These results let assume that Ti-doped graphite can be a promising armour material for divertor plasmafacing components.

\section{Acknowledgements}

This work has been funded by the European Community within the ExtreMat Integrated Project of the FP6 (NMP3-CT-2004-500253), and by the Spanish Ministry for Science and Education (ENE200614577-C04-04/FTN and MAT2004-22921-E). 


\section{References}

[1] G. Federici et al., J. Nucl. Mater. 313-316 (2003) 11-22.

[2] A.T. Peacock, M. Merola, M.A. Pick, R. Tivey, Phys. Scr. T128 (2007) 23-28.

[3] J. Roth, Phys. Scr. T124 (2006) 37-43.

[4] J. Roth et al., J. Nucl. Mater. 363-365 (2007) 822-826.

[5] J. Compan, T.J. Renk, T. Hirai, J. Linke, Phys. Scr. T128 (2007) 246-249.

[6] J. Linke, S. Amouroux, E. Berthe, Y. Koza, W. Kühnlein, M. Rödig, Fus. Eng. Des. 66-68 (2003) 395-399.

[7] N. Ordás, C. García-Rosales, S. Lindig, M. Balden, H. Wang, Phys. Scr. T111 (2004) 190-194.

[8] I. López-Galilea, C. García-Rosales, G. Pintsuk, J. Linke, Phys. Scr. T128 (2007) 60-65.

[9] E. de Juan Pardo, M. Balden, B. Cieciwa, C. García-Rosales, J. Roth, Phys. Scr. T111 (2004) 62-67.

[10] M. Balden, E. Oyarzabal, E. de Juan Pardo, K. Durocher, J. Roth, C. García-Rosales, Phys. Scr. T103 (2003) 38-42.

[11] O. Kubaschewski, E.L.L. Evans, C.B. Alcock, Metallurgical Thermochemistry, 4th, Pergamon Press, Oxford, 1967.

[12]Haipeng Qiu, Yongzhong Song, Lang Liu, Gengtai Zhai, Jingli Shi, Carbon 41 (2003) 973-978.

[13]I. López-Galilea, N. Ordás, C. García-Rosales, S. Lindig, this proceedings

[14] M. Balden, J. Roth, J. Nucl. Mater. 280 (2000) 39-44.

[15]J. Roth, C. García-Rosales, Nucl. Fusion 36 (1996) 1647-1659, with corrigendum Nucl. Fusion 37 (1997) 897.

[16] M. Bisio et al., Fus. Eng. Des. 75-79 (2005) 277-283.

[17] J. Roth, J. Nucl. Mater. 266-269 (1999) 51-57. 


\section{Table Captions}

Table 1: Typical properties of the undoped and Ti-doped materials [13]. The last two columns show parameters measured after the electron beam thermal loads. 


\section{Figure Captions}

Figure 1: Fluence dependence of the total erosion yield of Ti-doped graphite $A T$ for $30 \mathrm{eV} \mathrm{D}$ at $630 \mathrm{~K}$, $200 \mathrm{eV} \mathrm{D}$ at $620 \mathrm{k}$ and $200 \mathrm{eV}$ at $820 \mathrm{~K}$. The corresponding erosion yield for undoped carbon is indicated for each condition [16].

Figure 2: $\quad$ Surface morphology of Ti-doped graphite AT before (a) and after (b) erosion at $30 \mathrm{eV} \mathrm{D}$ impact and $630 \mathrm{~K}$ (accumulated fluence $1.26 \times 10^{25} \mathrm{D} / \mathrm{m}^{2}$ ).

Figure 3: Particle emission patterns of the different materials measured by digital imaging during electron beam loading. Top: comparison between materials A, AT and ATS. Bottom: particle emission during the $1^{\text {st }}$ and during the $10^{\text {th }}$ consecutive shot on the ATS material, and corresponding absorbed current by the test samples.

Figure 4: Brazing of Ti-doped graphite $A T$ to $\mathrm{Mo}$ interlayer using $\mathrm{Cu}$ active brazing alloy. 
13th International Conference on Fusion Reactor Materials (ICFRM-13)

10.-14. December 2007, Nice, France

Table 1

\begin{tabular}{lllllllll}
\hline $\begin{array}{l}\text { Sample } \\
\text { code }\end{array}$ & Dopant & $\begin{array}{l}\text { Density } \\
\left(\mathrm{g} / \mathrm{cm}^{3}\right)\end{array}$ & $\begin{array}{l}\text { Total } \\
\text { porosity } \\
(\mathrm{Vol} \%)\end{array}$ & $\begin{array}{l}\text { Open } \\
\text { porosity } \\
(\mathrm{Vol} \%)\end{array}$ & $\begin{array}{l}\text { Thermal } \\
\text { conductivity } \\
\text { at RT } \\
(\mathrm{W} / \mathrm{mK})\end{array}$ & $\begin{array}{l}\text { Flexural } \\
\text { strength } \\
(\mathrm{MPa})\end{array}$ & $\begin{array}{l}\text { Weight loss } \\
\text { per shot } \\
\left(\mu \mathrm{g} / \mathrm{mm}^{2}\right)\end{array}$ & $\begin{array}{l}\text { Crater } \\
\text { depth } \\
(\mu \mathrm{m})\end{array}$ \\
\hline $\mathrm{A}$ & None & $1.86-1.94$ & $13-17$ & $\sim 90 \%$ of $\mathrm{P}_{\text {tot }}$ & $70-85$ & $50 \pm 10$ & 55.0 & - \\
$\mathrm{AT}$ & $4 \mathrm{at} \% \mathrm{Ti}$ & $2.01-2.13$ & $8-13$ & $0-2$ & $115-218$ & $100 \pm 10$ & 31.1 & $\sim 11$ \\
ATS & $\begin{array}{l}4 \mathrm{at} \% \mathrm{Ti}+ \\
0.5 \mathrm{at} \% \mathrm{Si}\end{array}$ & $2.07-2.09$ & $10-12$ & 0 & $189-201$ & $92 \pm 2$ & 28.8 & $\sim 7$ \\
\hline
\end{tabular}


Figure 1

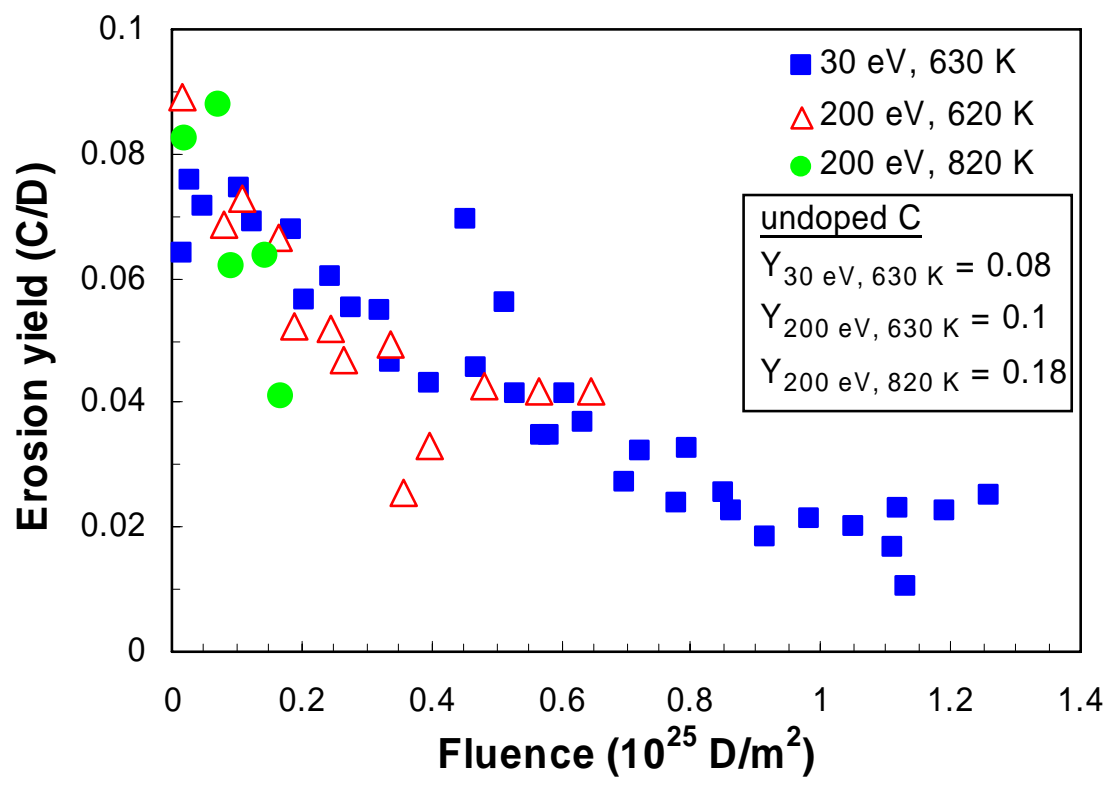


Figure 2
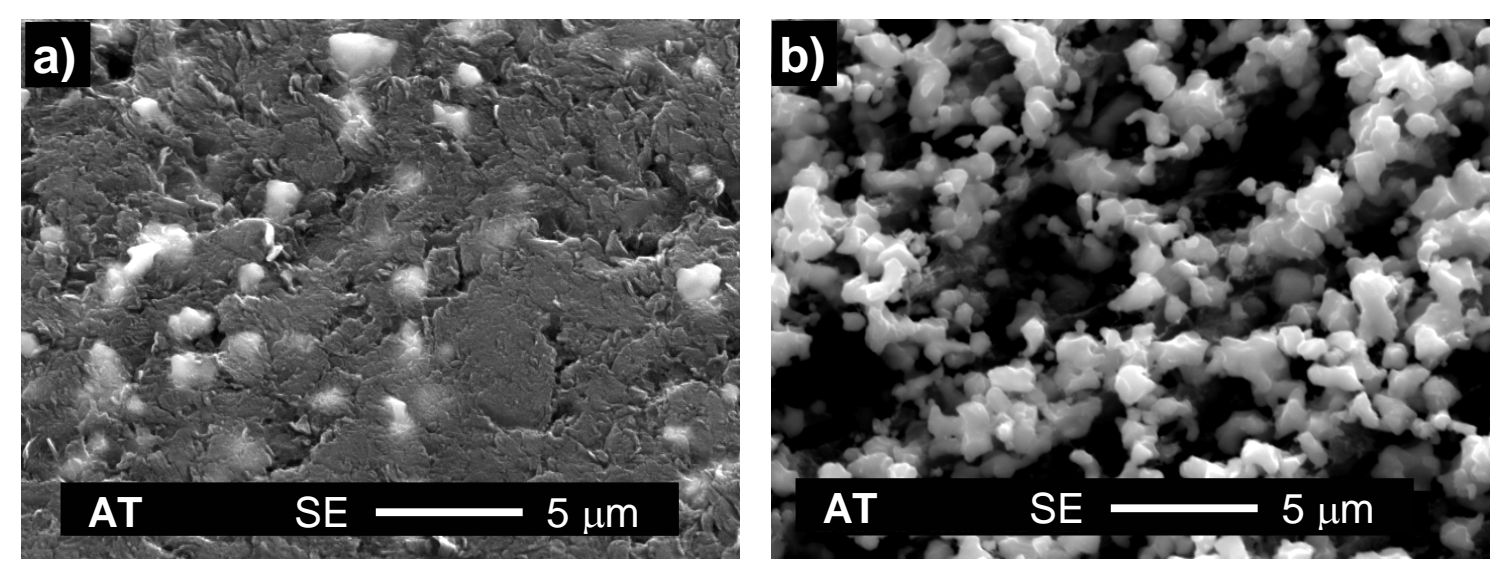
Figure 3

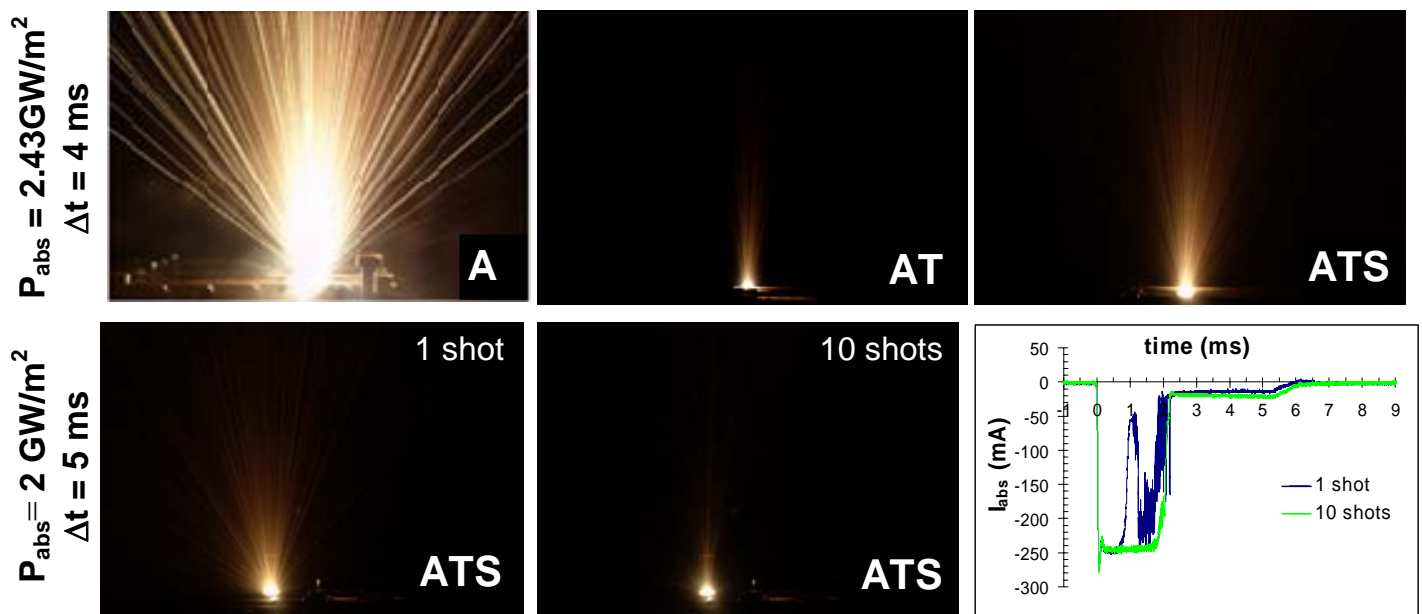


Figure 4

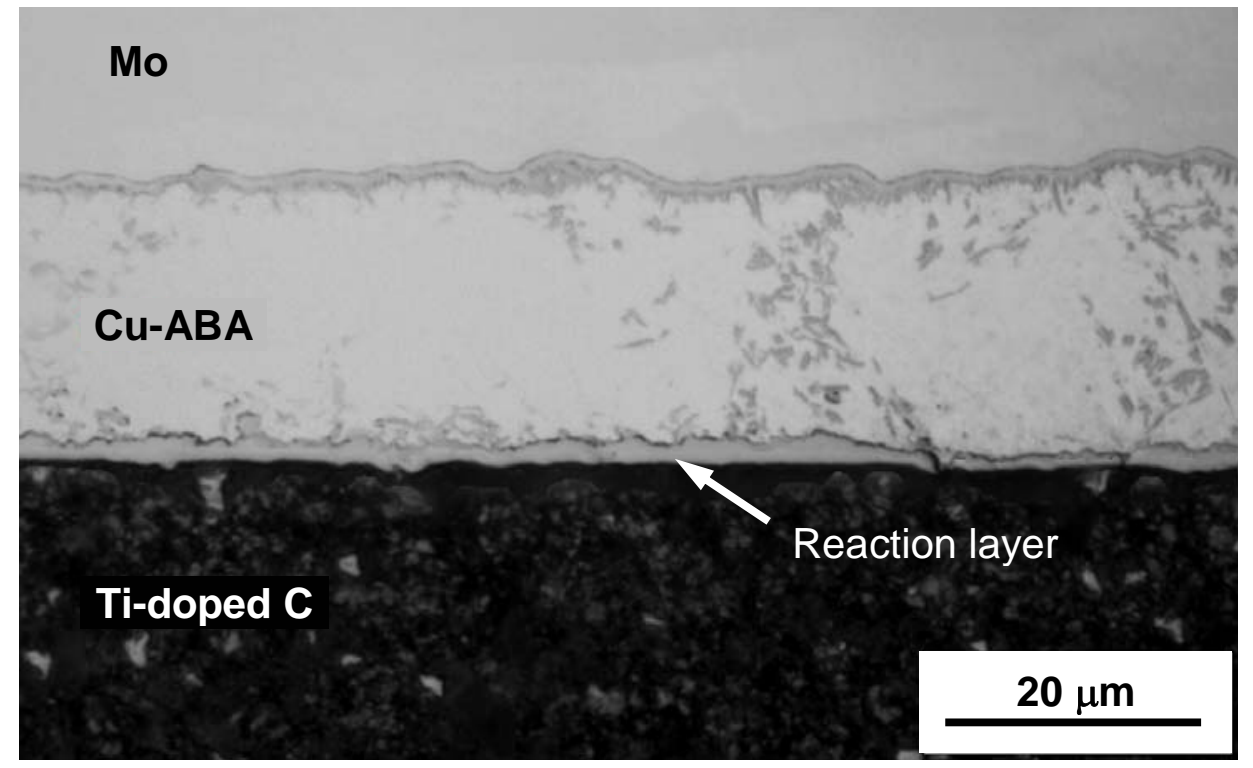

